\title{
A MANUTENÇÃO DE ATIVOS NO CONTEXTO DA INDÚSTRIA 4.0: UMA ANÁLISE BIBLIOMÉTRICA E SISTEMÁTICA
}

\author{
ASSET MAINTENANCE IN THE CONTEXT OF INDUSTRY 4.0: \\ A BIBLIOMETRIC AND SYSTEMATIC ANALYSIS
}

Recebido em: 02 jul. 2020

Aprovado em: 11 ago 2020

Versão do autor aceita publicada online: 11 ago 2020

Publicado online: 25 jun. 2021

\section{Como citar esse artigo - American Psychological Association (APA):}

Delecrodio, T. A. V., Neves, G. R., \& Lucato, W. C. (2023, jan./mar). A manutenção de ativos no contexto da Indústria 4.0: uma análise bibliométrica e sistemática. Exacta, 21(1), 23-52. https://doi.org/10.5585/exactaep.2021.17589

Submeta seu artigo para este periódico $\beta$

Dados Crossmark 



\title{
A MANUTENÇÃO DE ATIVOS NO CONTEXTO DA INDÚSTRIA 4.0: UMA ANÁLISE BIBLIOMÉTRICA E SISTEMÁTICA
}

\author{
ASSET MAINTENANCE IN THE CONTEXT OF INDUSTRY 4.0: \\ A BIBLIOMETRIC AND SYSTEMATIC ANALYSIS
}

\section{Thays Aparecida Vendramin Delecrodio Glauber Roger Neves Wagner Cezar Lucato}

\section{Resumo}

Este artigo tem como objetivo investigar a produção científica recente sobre a manutenção de ativos no contexto da Indústria 4.0. Para isso foi feita uma revisão sistemática da literatura, mesclando um estudo bibliométrico e a análise de conteúdo dos artigos recentes que tratam sobre o tema de interesse deste trabalho. Como resultado foram identificados 225 artigos dos quais 7 que tratam sobre o tema de geração de economia de recursos no custo de manutenção foram considerados para uma análise mais aprofundada. Como conclusão pôde-se observar que no contexto da manutenção na era da Indústria 4.0, ainda há uma carência e necessidade de estudos de aplicações práticas, que proporcionem uma aprendizagem adequada e que ajude no entendimento e melhoria das tecnologias. Este trabalho traz contribuições teóricas na medida que identifica lacunas de pesquisa e sugeriu algumas oportunidades a serem consideradas em estudos futuros sobre o tema. Para a prática, os conhecimentos aqui expostos poderão se tornar um guia aos gestores das áreas de Manutenção sobre os principais tópicos que associam a gestão da manutenção de ativos e os requisitos das tecnologias da 14.0.

Palavras chave: Manutenção de ativos; Indústria 4.0; Custo; Bibliometria; Análise sistemática.

\section{Abstract}

This article aims to investigate the recent scientific production on asset maintenance in the context of Industry 4.0. For this, a systematic review of the literature was made, combining a bibliometric study and content analysis of recent articles dealing with the topic of interest in this work. As a result, 225 articles were identified, of which 7 that deal with the topic of generating savings in the cost of maintenance were considered for further analysis. As a conclusion, it was observed that in the context of maintenance in the era of industry 4.0, there is still a shortage and need for studies and practical applications, which provide adequate learning and help in understanding and improving technologies. This work brings theoretical contributions as it identifies research gaps and suggested some opportunities to be considered in future studies on the subject. For the practice the knowledge exposed here may become a guide for managers in the Maintenance areas on the main topics that associate asset maintenance management and the requirements of I 4.0 technologies.

Keywords: asset maintenance; Industry 4.0; Cost; Bibliometry; Systematic analysis. 


\section{Introdução}

A indústria moderna demanda cada vez mais melhorias em seus processos, aspirando pelo aumento de sua produtividade e dependendo, necessariamente, da manutenção de suas máquinas e equipamentos, razão pela qual o setor de manutenção precisa de um trabalho eficaz para garantir a confiabilidade e a disponibilidade dos ativos. Dessa forma, obtém-se uma melhor utilização da sua capacidade frente à demanda, isto é, a manutenção atua nas organizações para evitar as falhas e protege suas instalações físicas, o que permite a continuidade do processo e garante, também, precisão, segurança e economia nos custos (Blanchard, 2003). Nesta perspectiva, a conquista de um sistema de gestão da manutenção de ativos satisfatório, de modo a garantir o bom funcionamento dos equipamentos, empregados motivados, planejamento e estrutura adequados e alinhamento entre as diretrizes e as metas individuais de cada funcionário, constitui uma parcela significativa para a gestão de uma organização (Campos, 2013).

Estudos anteriormente realizados mostraram que os custos de manutenção podem atingir de $15 \%$ a $70 \%$ do custo total de fabricação de um produto ou até mesmo o lucro líquido anual de uma empresa (Mobley, 2002; Ding \& Kamaruddin, 2015). Um estudo publicado pela ABRAMAN (2013) revela que o custo anual de manutenção da indústria brasileira representa, em média, 4,69\% do PIB do país. Nesta conjuntura, torna-se cada vez mais necessário que estratégias de manutenção adequadas possam ser implantadas com o propósito de melhorar a confiabilidade e disponibilidade de sistemas de produção tendo como objetivo garantir qualidade, pontualidade de entrega e custos competitivos dos produtos (Ding \& Kamaruddin, 2015; He, Gu, \& Chen, 2017).

Conforme Choi, Kang, Jung, Kulvatunyou e Morris (2016), a Indústria 4.0 é a quarta geração da era industrial, caracterizada pela utilização de sistemas inteligentes e pela capacidade de tomar decisões autônomas, com elevado grau de automação. A Indústria 4.0 surge com a crescente da automação dos processos produtivos, juntamente com o avanço da tecnologia da Internet e a tecnologia desenvolvida no campo dos objetos inteligentes (produtos e máquinas) e tem impactado o setor de gestão de manutenção de ativos por meio de soluções que facilitam o gerenciamento dos sistemas de produção, proporcionando uma maior capacidade de operação e de planejamento. Isto também se deve ao rápido desenvolvimento da tecnologia da informação e da ciência da computação e suas integrações com as atividades de produção industrial onde inúmeras possibilidades e desafios são identificados para o desenvolvimento de novas aplicações (Babiceanu \& Seker, 2016; Al-Ahmari \& Li, 2016).

A Indústria 4.0 trata-se de uma transformação digital da fabricação, alavancada por tecnologias como Big Data/Analytics, IoT-Internet das Coisas, exigindo a convergência de Tecnologia da Informação e Tecnologia Operacional, robótica, computação cognitiva e processos de fabricação. Visando ter fábricas conectadas, fabricação inteligente descentralizada e sistemas de auto otimização (European 
Parliament, 2015). Uma das áreas de aplicação das tecnologias da Indústria 4.0 é a manutenção na forma de autoaprendizagem e de sistemas inteligentes, que podem antever falhas, fazer diagnósticos e acionar ações de manutenção (Lee, Kao, \& Yang, 2014). Além disso, a aplicação de tecnologias da Indústria 4.0 na manutenção permite que as empresas maximizem a vida útil de seus equipamentos de produção, evitando paralisações não planejadas, minimizando o tempo de inatividade, aumentando a segurança dos processos e das pessoas, reduzindo o consumo de energia e recursos e economizando custos (Jasiulewicz-Kaczmarek \& Gola, 2019).

Ademais, a Indústria 4.0 aborda e cria soluções para alguns dos desafios do mundo contemporâneo, como a eficiência energética, de recursos e produção urbana. Permite que o trabalho seja organizado, levando em consideração as mudanças demográficas e fatores sociais. Alguns sistemas podem proporcionar a execução de tarefas rotineiras, permitindo que os trabalhadores se concentrem em atividades criativas e de valor agregado. A flexibilidade do trabalho, por meio da utilização de tecnologias da Indústria 4.0, permitirá que a sociedade combine suas tarefas, vida privada e desenvolvimento profissional de forma mais eficaz, promovendo um melhor equilíbrio entre vida profissional e pessoal (Moraes \& Lepikson, 2017).

Com base nessas observações, a realização de pesquisas que identifiquem trabalhos científicos que abordam a temática de manutenção de ativos no âmbito da Indústria 4.0 se faz necessária para que se possam identificar eventuais lacunas que venham a servir de orientadores para pesquisas e desenvolvimentos futuros. Nesse sentido, este artigo tem como propósito central investigar a produção científica recente a respeito da manutenção de ativos no contexto da Indústria 4.0, o que é feito por meio da revisão sistemática da literatura, mesclando um estudo bibliométrico e a análise de conteúdo de artigos recentes que tratam sobre o tema de interesse deste trabalho.

\section{A manutenção no contexto de Indústria 4.0}

Para Branco (2008) a manutenção representa a união das atuações administrativas e técnicas, envolvendo o gerenciamento de ações desenvolvidas para repor ou conservar um determinado item de modo que possa mantê-lo continuamente nas suas condições normais de operação. Também pode ser considerada como o campo da Engenharia cujo objetivo é a conservação a longo prazo dos ativos fixos de uma empresa, garantindo plenamente as suas características funcionais (Mirshawka \& Olmedo, 1993). A manutenção está no centro de toda operação de uma empresa. Nesse sentido, Pinto (2013) reforça que é inútil o gestor de operações tentar obter ganhos de produtividade se os seus equipamentos possuem baixo desempenho devido às deficiências em sua manutenção.

Dentre os muitos benefícios da manutenção, Slack, Brandon-Jones e Johnston (2018) citam a segurança melhorada, a confiabilidade aumentada, qualidade do produto maior, custos de operações mais baixos, vida útil mais longa, e preço residual maior. Desse modo, a manutenção contribui 
efetivamente no processo de garantir lucro e assegurar valor à organização, seja como um elo da cadeia de valor ou quanto uma micro operação dentro da macro operação de produção (Barros \& Lima, 2011).

A manutenção pode ser classificada em três diferentes tipos. A definição de cada tipo de manutenção, segundo a NBR 5462 (ABNT, 1994), é:

- Manutenção Corretiva: aquela realizada depois que uma pane ocorre e que tem como objetivo reconduzir o item com problemas a seu estado anterior à pane, de maneira que possa voltar a executar a sua função requerida;

- Manutenção Preventiva: aquela feita em intervalos predefinidos e que tem por objetivo reduzir a probabilidade da ocorrência de falhas ou a deterioração do item de maneira a provocar o seu mau desempenho;

- Manutenção Preditiva: aquela que permite o funcionamento adequado de um item, como decorrência da utilização de técnicas de análise que minimizam a necessidade de realizar tanto manutenções preventivas como corretivas.

Segundo Mobley (2002), o objetivo da manutenção é prevenir todas as perdas causadas por problemas nos equipamentos. A missão dos responsáveis pela manutenção é o de atingir e manter:

- Disponibilidade ideal - A capacidade produtiva de uma fábrica é em parte determinada pela disponibilidade dos sistemas de produção. A equipe de manutenção deve assegurar que todos os equipamentos estão em boas condições de operação;

- Condições operacionais ideais - Deve ser assegurado que todos os equipamentos e sistemas estão nas suas condições de operação ideais;

- Utilização máxima dos recursos da manutenção - A equipe de manutenção controla uma parte substancial do orçamento total de operações na maioria das fábricas. Além disso, normalmente gere o inventário de peças, contratação de empresas externas e requisições de recursos em componentes para reparação ou equipamentos substitutos.

- Vida útil máxima do equipamento - Estender a vida útil de um item é uma das formas de reduzir os custos de manutenção;

- Mínimo de inventário de peças - Reduções de inventário deve ser um dos grandes objetivos do departamento da manutenção. No entanto, a redução não deve colocar em causa os primeiros quatro objetivos. Com tecnologias de manutenção preventiva disponíveis nos dias de hoje, a manutenção pode antecipar a necessidade de um equipamento específico ou componentes com antecedência suficiente para adquiri-las com base na necessidade; 
- Capacidade de reagir rapidamente - Nem todas as avarias podem ser evitadas. Assim, o setor de manutenção deve conseguir reagir rapidamente a uma avaria inesperada.

Roy, Stark, Tracht, Takata, \& Mori (2016) relatam que produtos de alto valor são tipicamente tecnológicos, caros e críticos quanto à confiabilidade, exigindo uma manutenção contínua durante todo o seu ciclo de vida. Exemplos de ativos de alto valor incluem máquinas-ferramentas, motores de aeronaves, usinas nucleares, trens, equipamentos de defesa, automóveis, equipamentos médicos, turbinas eólicas, entre outros.

A manutenção de ativos permite a incorporação de novas tecnologias no planejamento, implementação, monitoramento e análise de processos de manutenção, como: sensores e dispositivos inteligentes (Mueller, Chen, \& Riedel, 2017; Roy et al., 2016; Zhong, Wang, \& Xu, 2017); sistema computadorizado de gerenciamento de informação (Lopes et al., 2016; Rødseth, Schjølberg, \& Marhaug, 2017); ferramentas de diagnósticos e de prognósticos (Li, Wang, \& Wang, 2017; computação em nuvem (Al-Gumaei et al., 2018; Dillon, Wu, \& Chang, 2010; Zhong et al., 2017); simulação e modelagem (Alrabghi, Tiwari, \& Savill, 2017; Antosz \& Ratnayake 2019); realidade aumentada (SuarezWarden, Mendıvil, Ramırez, \& Garcıa-Lumbreras, 2015; del Amo, Erkoyuncu, Roy, \& Wilding, 2018). Essas tecnologias definem a próxima geração na abordagem de manutenção de equipamentos na era da Indústria 4.0 (Jasiulewicz-Kaczmarek \& Gola, 2019).

Conforme Lee, Bagueri e Kao (2015), a Indústria 4.0 envolve as mais recentes inovações tecnológicas incluindo automação, tecnologia da informação e controle, aplicadas aos processos de produção. Utilizando os Sistemas Cyber-Físicos e a Internet das Coisas, a manufatura busca padrões mais eficazes, customizáveis e independentes. As novas fábricas inteligentes gerarão impactos nos diversos setores do mercado (Lee et al., 2015).

Para Brettel, Friederichsen, Keller e Rosenberg (2014), os fundamentos para a implantação da Indústria 4.0 são:

Capacidade de operação em tempo real que envolve a aquisição e o tratamento de dados de manufatura de maneira quase instantânea, permitindo que as decisões sejam tomadas em tempo real;

Virtualização - a Indústria 4.0 propõe a utilização de uma cópia virtual das fabricas inteligentes, possibilitando o rastreamento e controle remoto dos processos de produção com a utilização de sensores distribuídos por toda a planta;

Descentralização - o sistema cyber-físico permitirá a tomada de decisões em tempo real atendendo as prioridades da produção. Ainda, as máquinas poderão gerar informações sobre seu ciclo operacional de maneira que os diversos componentes da fábrica inteligente poderão aperfeiçoar os processos de produção atuando de forma descentralizada; 
Modularidade - utilização ampla de módulos de produção que poderão atender diferentes tipos e níveis de demanda por meio da adoção de diversas combinações que podem ser acopladas ou desacopladas. Isso gera a desejada flexibilidade para facilmente alterar o sequenciamento da produção.

De acordo com Stock e Seliger (2016), na Indústria 4.0, os produtos, os stakeholders (clientes, funcionários ou fornecedores), e os equipamentos de fabricação estão embutidos em uma rede virtual, trocando dados entre as diferentes fases do ciclo de vida do produto. Este ciclo de vida consiste na fase de aquisição da matéria-prima, a fase de fabricação, contendo o desenvolvimento do produto, a engenharia do sistema industrial e a fabricação do produto, a fase de uso e serviço, a fase do fim de vida, englobando a reutilização, remanufatura, reciclagem, recuperação e eliminação, bem como o transporte entre todas as fases.

Os métodos atuais de manutenção de equipamentos, em sua maioria, dependem de um sistema de alarmes e da boa vontade de um operador em relatar as falhas apresentadas pelo equipamento ao departamento de manutenção da empresa. A falha precisa ser exatamente localizada e resolvida, podendo ocorrer um desligamento no processo de produção. Com o apoio das tecnologias habilitadores da Indústria 4.0, os dados do equipamento podem ser coletados em tempo real, incluindo alarmes, registros e status do dispositivo, a fim de avaliar a condição de saúde dos ativos e detectar preventivamente as falhas. Portanto, a manutenção na Indústria 4.0 é proativa e pode encontrar os problemas antecipadamente. Nesta perspectiva, as oportunidades de desenvolvimento de manutenção 4.0 no ciclo de vida dos produtos são enormes, podendo gerar receita e lucro adicionais para as empresas (Wan, Tang, Li, Wang, Liu, Abbas, \& Vasilakos, 2017). No entanto, esses processos, bem como a implementação da Indústria 4.0 em geral, representam ameaças diante dos grandes investimentos necessários e à lucratividade incerta (Arnold, Kiel, \& Voigt, 2016; Erol, Jäger, Hold, Ott, \& Sihn, 2016). Além disso, as empresas entendem a transformação de seus modelos de negócios atuais para a Indústria 4.0 como um desafio (Herrmann, Schmidt, Kurle, Blume, \& Thiede, 2014; Hirsch-Kreinsen, 2014).

\section{Métodos}

De acordo com Gil (2010), este artigo é descritivo e exploratório com abordagem qualitativa e quantitativa, a partir da realização de um estudo bibliométrico e revisão da literatura, com utilização de ferramentas da estatística descritiva.

A análise bibliométrica realizada neste trabalho foi composta por: uma busca sistemática de publicações sobre os assuntos pesquisados, ou seja, a coleta de dados; e a seleção de alguns artigos que seriam mais relevantes e aderentes ao objetivo do estudo, e que foram discutidos.

As bases de dados definidas e utilizadas foram a Science Direct, Scopus e Web of Science, devido ao grande volume de publicações e a popularidade na área de engenharia e ciência da computação, 
além de estarem entre as maiores associações científicas com importante renome e credibilidade na área acadêmica.

O termo de pesquisa é resultante de algumas constatações e passaram por algumas adaptações após a realização de testes. Durante as primeiras pesquisas nas bases, verificou-se que o assunto Indústria 4.0 tem sido intensamente estudado nos últimos anos e, portanto, um número considerável de publicações pôde ser percebido dentre os resultados das pesquisas bibliográficas realizadas. Como o presente artigo se concentra na análise envolvendo trabalhos cujo tema é Indústria 4.0 e manutenção, - Quadro 1 indica os termos de busca e as palavras-chave essenciais utilizadas com expressões booleanas (AND e OR), que permitem a combinação de palavras-chave no sentido de se aproximar o melhor possível de um termo específico, referentes a pesquisa de artigos disponíveis nas bases de dados.

\section{Quadro 1}

Termo de busca formulado para busca nas bases científicas

\begin{tabular}{|l|l|l|}
\hline Palavras-chave de MCDM & Operador Lógico & Palavras-chave de métodos MCDM \\
\hline ("industry 4.0" OR "industrie 4.0") & AND & ("maintenance") \\
\hline
\end{tabular}

Fonte: Os autores.

As buscas foram realizadas nas bases de dados durante o mês de novembro de 2019, pesquisando os termos nos títulos, resumos e palavras-chave. Após a busca dos termos nas bases, foi realizada um refinamento na pesquisa, aplicando-se os filtros de tipo de documento para apenas "artigos" publicados em periódicos, no período de 2014 a 2019. Os resultados encontrados estão expressos na Tabela 1.

Em uma etapa seguinte, os dados das pesquisas nas bases foram exportados para o software EndNote, o que viabilizou a exclusão dos trabalhos duplicados automaticamente. O EndNote é um aplicativo desenvolvido pela empresa Thomson Reuters, que proporciona a organização e gerenciamento de referências bibliográficas. O sistema permite a aplicação de vários filtros de pesquisa, análise simultânea de grande quantidade de referências e a possibilidade de exportação dos dados para o Microsoft Excel, o que facilita a realização de uma análise bibliométrica. Em seguida, foi realizada uma análise individual de cada título e resumo, avaliando a adequação de cada artigo ao assunto aqui pesquisado, eliminando-se os documentos irrelevantes. Ao final se obteve um total de 225 artigos para serem estudados. 


\section{Tabela 1}

Frequência do número de produção científica por base de dados

\begin{tabular}{|c|c|c|c|}
\hline Base de Dados & Busca Inicial & $\begin{array}{l}\text { Aplicação de Filtro } \\
\text { (artigos de 2014-2019) }\end{array}$ & $\begin{array}{c}\text { Resultado final } \\
\text { (após elim. duplicados / } \\
\text { irrelevantes) }\end{array}$ \\
\hline Science Direct & 87 & 82 & \multirow{3}{*}{225} \\
\hline Scopus & 550 & 163 & \\
\hline Web of Science & 364 & 175 & \\
\hline Total: & 1001 & 420 & 225 \\
\hline
\end{tabular}

Fonte: Os autores.

Na sequência, executou-se o desenvolvimento das estatísticas dos trabalhos explorados, elaborando figuras, quadros e gráficos a respeito dos autores, periódicos, citações, entre outros. Também, a partir da pesquisa bibliométrica, foi desenvolvido uma nuvem das palavras-chave por meio do software Wordle, dando maior destaque às palavras-chave mais presentes nos textos de origem.

Após o levantamento dos dados numéricos, uma outra análise de conteúdo dos artigos foi realizada. Desta vez, por meio do software EndNote, buscou-se dentre os 225 artigos resultantes apenas os trabalhos que abrangem o termo "Cost" redigido no título, resumo ou palavra-chave. Esta nova sondagem relacionou 54 artigos. A seguir, investigou-se os conteúdos, argumentos e resultados obtidos nos documentos. Diante disso, considerou-se relevante 7 documentos para que fossem analisados na íntegra, apontando diferentes abordagens e contribuições sobre o tema de geração de economia de recursos no custo de manutenção. Este tema foi estabelecido pois uma estratégia de manutenção de ativos adequada e otimizada é necessária para manter ou restaurar o sistema em um estado em que o equipamento pode completar as tarefas de produção necessárias com custos mínimos. (Changyou, Haiyang, Song, Yimin, \& Zhenyuan, 2014; He, Han, Gu, \& Chen, 2018; Xia, Xi, Lee, \& Zhou, 2011).

\section{Análise dos resultados}

Neste item são levantadas as principais particularidades da análise bibliométrica, sendo discutidos os resultados encontrados.

\subsection{A evolução da produção científica}

Verificou-se primeiramente a frequência de artigos por ano entre os 225 artigos publicados no período estudado. De acordo com a Figura 1, observa-se que entre os anos 2014 e 2015 não houve um número expressivo de publicações, com apenas 9 artigos neste período. A partir de 2016 é possível 
verificar um crescimento em relação aos anos anteriores, ressaltando-se o pico ocorrido em 2019, até o momento, com 83 artigos publicados.

Figura 1

Frequência absoluta (n) da evolução da produção científica de artigos no período de 2014 a 2019

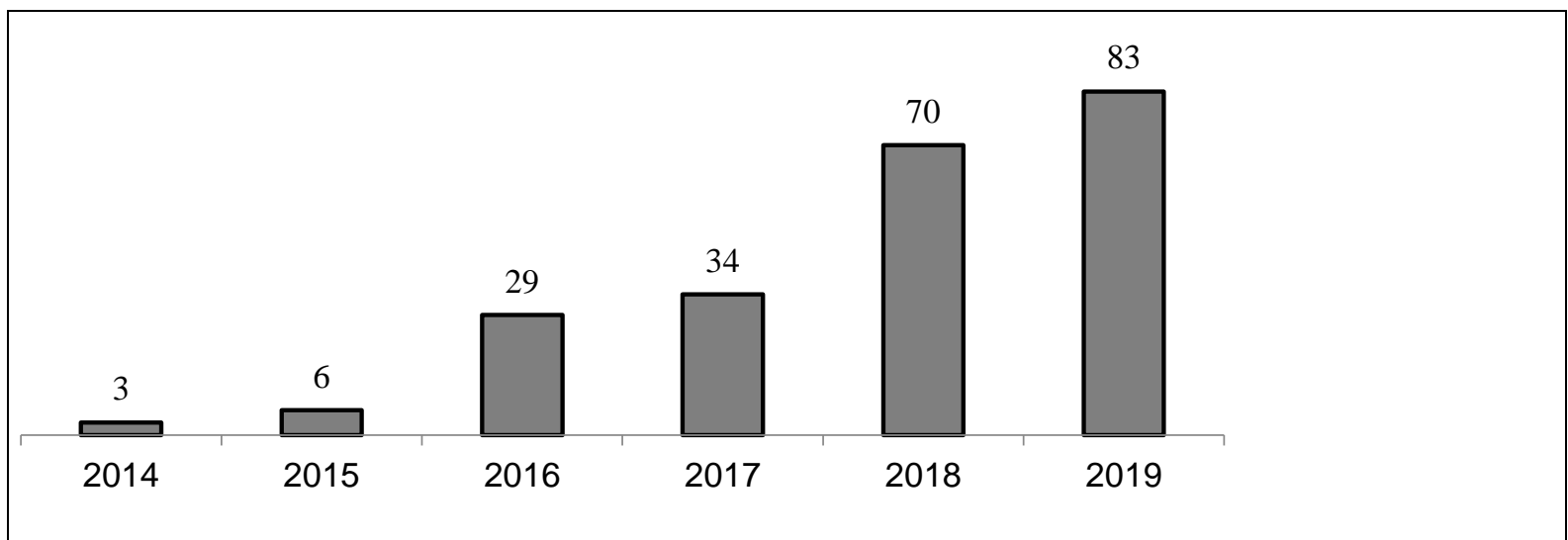

Fonte: Os autores.

Também, verificou-se as referências mais mencionadas entre os 225 artigos publicados. Por não haver recomendação nesse sentido na literatura, decidiu-se considerar as publicações citadas 30 vezes ou mais. Com isso, foram obtidos 10 artigos, que estão mostradas por ordem decrescente de citações na Tabela 2. O artigo de Stock e Seliger (2016), Opportunities of Sustainable Manufacturing in Industry 4.0, obteve o maior índice de menções $(n=192)$ no período analisado. 
Tabela 2

Os 10 trabalhos mais referenciados no período de 2014 a 2019

\begin{tabular}{|c|c|c|c|c|}
\hline Rank & Título do Artigo & Autores & Título da fonte & Citações \\
\hline 10 & $\begin{array}{l}\text { Opportunities of Sustainable Manufacturing } \\
\text { in Industry } 4.0\end{array}$ & $\begin{array}{l}\text { Stock e Seliger } \\
(2016)\end{array}$ & $\begin{array}{l}\text { 13th Global } \\
\text { Conference on } \\
\text { Sustainable } \\
\text { Manufacturing - } \\
\text { Decoupling Growth } \\
\text { from Resource Use }\end{array}$ & 192 \\
\hline 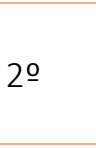 & $\begin{array}{l}\text { A Manufacturing Big Data Solution for Active } \\
\text { Preventive Maintenance }\end{array}$ & $\begin{array}{l}\text { Wan et al. } \\
(2017)\end{array}$ & $\begin{array}{l}\text { IEEE Transactions on } \\
\text { Industrial } \\
\text { Informatics }\end{array}$ & 85 \\
\hline 30 & $\begin{array}{l}\text { Continuous maintenance and the future - } \\
\text { Foundations and technological challenges }\end{array}$ & $\begin{array}{l}\text { Roy et al. } \\
(2016)\end{array}$ & $\begin{array}{l}\text { CIRP Annals - } \\
\text { Manufacturing } \\
\text { Technology }\end{array}$ & 73 \\
\hline 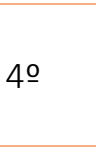 & $\begin{array}{l}\text { Digital Twin and Big Data Towards Smart } \\
\text { Manufacturing and Industry 4.0: } 360 \text { Degree } \\
\text { Comparison }\end{array}$ & $\begin{array}{l}\text { Qi e Tao } \\
(2018)\end{array}$ & IEEE Access & 70 \\
\hline 50 & $\begin{array}{l}\text { Digital Twin Shop-Floor: A New Shop-Floor } \\
\text { Paradigm Towards Smart Manufacturing }\end{array}$ & $\begin{array}{l}\text { Tao e Zhang } \\
\text { (2017) }\end{array}$ & IEEE Access & 62 \\
\hline 6음 & $\begin{array}{l}\text { An industrial big data pipeline for data-driven } \\
\text { analytics maintenance applications in large- } \\
\text { scale smart manufacturing facilities }\end{array}$ & $\begin{array}{l}\text { O’Donovan, } \\
\text { Leahy, Bruton } \\
\text { e O’Sullivan, } \\
\text { (2015) }\end{array}$ & Journal of Big Data & 50 \\
\hline 70 & $\begin{array}{l}\text { Cyber-physical Systems Architecture for Self- } \\
\text { Aware Machines in Industry 4.0 Environment }\end{array}$ & $\begin{array}{l}\text { Bagheri, Yang, } \\
\text { Kao e Lee } \\
(2015)\end{array}$ & $\begin{array}{l}\text { 15th IFAC } \\
\text { Symposium on } \\
\text { Information Control } \\
\text { Problems in } \\
\text { Manufacturing }\end{array}$ & 45 \\
\hline 80 & $\begin{array}{l}\text { Industrial Process Monitoring in the Big } \\
\text { Data/Industry 4.0 Era: From Detection, to } \\
\text { Diagnosis, to Prognosis }\end{array}$ & $\begin{array}{l}\text { Reis e Gins } \\
(2017)\end{array}$ & Processes & 38 \\
\hline 9음 & $\begin{array}{l}\text { A Digital Twin-Based Approach for Designing } \\
\text { and Multi-Objective Optimization of Hollow } \\
\text { Glass Production Line }\end{array}$ & $\begin{array}{l}\text { Zhang, Liu, } \\
\text { Chen, Zhang, } \\
\text { e Leng (2017) }\end{array}$ & IEEE Access & 35 \\
\hline 10 은 & $\begin{array}{l}\text { Industrial Big Data in an Industry } 4.0 \\
\text { Environment: Challenges, Schemes, and } \\
\text { Applications for Predictive Maintenance }\end{array}$ & $\begin{array}{l}\text { Yan, Meng, Lu } \\
\text { e Li (2017) }\end{array}$ & IEEE Access & 31 \\
\hline
\end{tabular}

Fonte: Os autores.

Com relação às entidades nas quais as pesquisas foram realizadas, a Tabela 3 mostra o ranking das 13 primeiras com maior número $(n \geq 4)$ de autorias de publicações. Nos 225 resultados da pesquisa foram encontradas 408 entidades de pesquisa com pelo menos uma autoria nas bases pesquisadas. Entre as 13 mais bem colocadas, constata-se que três são italianas. A China e a Suécia possuem, cada uma, dois artigos publicados entre as primeiras classificadas. 
Tabela 3

Frequência absoluta de autorias de publicações associadas entidades nas quais foram realizadas as pesquisas no período de 2014 a 2019

\begin{tabular}{|c|c|c|c|c|}
\hline Ran & Instituição de Ensino & № Artigos & Cidade & País \\
\hline 10 & Politecnico di Milano & 8 & Milão & Itália \\
\hline 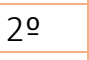 & University of Cambridge & 7 & Cambridge & Reino Unido \\
\hline \multirow{2}{*}{30} & Beihang University & 6 & Pequim & China \\
\hline & Shanghai Jiao Tong University & 6 & Xangai & China \\
\hline 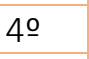 & Politecnico di Bari & 5 & Bari & Itália \\
\hline \multirow{8}{*}{50} & Brno University of Technology & 4 & Brno & $\begin{array}{l}\text { República } \\
\text { Tcheca }\end{array}$ \\
\hline & $\begin{array}{l}\text { Centre National de la Recherche Scientifique } \\
\text { CNRS }\end{array}$ & 4 & Paris & França \\
\hline & Chalmers University of Technology & 4 & $\begin{array}{c}\text { Gotemburg } \\
0\end{array}$ & Suécia \\
\hline & Indian Institute of Technology & 4 & Nova Délhi & Índia \\
\hline & Luleå University of Technology & 4 & Luleå & Suécia \\
\hline & Technische Universität Berlin & 4 & Berlin & Alemanha \\
\hline & Università degli Studi di Napoli Federico II & 4 & Nápoles & Itália \\
\hline & University of Patras & 4 & Patras & Grécia \\
\hline
\end{tabular}

Fonte: Os Autores.

O Politécnico di Milano ocupa o primeiro lugar com 8 autorias associadas, seguido pela University of Cambridge com 7. A autoria associada refere-se ao autor de uma publicação que informa ser associado à instituição. Por isso, um artigo pode ser considerado mais de uma vez, dependendo do número de autores.

Em referência à origem dos documentos, buscou-se captar a nacionalidade da instituição de afiliação dos coautores dos 225 trabalhos identificados. No total, encontrou-se 48 países com artigos publicados, sendo que apenas os quatro primeiros colocados totalizam mais de $59 \%$ dos artigos indexados no período pesquisado nas bases. As principais parcerias são com pesquisadores filiados a entidades de pesquisa alemãs ( $n=21,8 \%)$ seguida pela Itália $(n=14,1 \%)$ e China ( $n=13,3 \%)$, conforme destacado na Tabela 4.

\section{Tabela 4}

Número de coautorias por país de origem no período de 2014 a 2019 


\begin{tabular}{|c|c|c|}
\hline Rank & País & $\%$ \\
\hline 10 & Alemanha & $21,8 \%$ \\
\hline 20 & Itália & $14,1 \%$ \\
\hline 30 & China & $13,3 \%$ \\
\hline 40 & Reino Unido & $10,1 \%$ \\
\hline 50 & Estados Unidos & $7,2 \%$ \\
\hline 60 & Índia & $5,4 \%$ \\
\hline 70 & Suécia & $5,4 \%$ \\
\hline 80 & Espanha & $4,0 \%$ \\
\hline 9o & Áustria & $3,5 \%$ \\
\hline 10 o & República Checa & $3,1 \%$ \\
\hline
\end{tabular}

Fonte: Os Autores.

Deve-se mencionar que uma publicação, por ter vários autores, cada um deles conta como uma coautoria. Dos 10 países com maior número de associações em pesquisa, sete são europeus, dois são asiáticos e apenas um norte-americano.

Quanto ao número de publicações por autor, observou-se que nos 225 artigos publicados entre 2014 e 2019 foram contabilizados 758 autores diferentes, o que apresenta uma média de 3,4 autores por artigo. Além disso, dentre os 758 autores, 694 publicaram somente um artigo com a mesma temática de trabalho $(91,5 \%)$.

O Quadro2 mostra os autores mais profícuos observados no estudo realizado. Aqui foram contabilizados todos os trabalhos em que os autores foram listados também como coautores, já que a ordem de autoria não foi considerada. Os três autores que mais publicaram tiveram 4 trabalhos aceitos cada um.

\section{Quadro 2}

Frequência absoluta do número de produção científica por autor no período de 2014 a 2019 


\begin{tabular}{|c|c|c|c|c|c|c|}
\hline \multicolumn{7}{|c|}{ Autores } \\
\hline 4 artigos & \multicolumn{2}{|c|}{3 artigos } & \multicolumn{4}{|c|}{2 artigos } \\
\hline $\begin{array}{l}\text { Fumagalli, } \\
\text { L. }\end{array}$ & $\begin{array}{l}\text { Bordegoni, } \\
\text { M. }\end{array}$ & Koenig, F. & Ansari, F. & Hadas, Z. & $\mathrm{Li}, \mathrm{Z}$. & Samet, A. \\
\hline Macchi, M. & $\begin{array}{l}\text { Cattaneo, } \\
\text { L. }\end{array}$ & Kumar, M. & Berlin, C. & $\begin{array}{l}\text { Hammer, } \\
\text { M. }\end{array}$ & Lin, C. C. & $\begin{array}{l}\text { Scurati, G. } \\
\text { W. }\end{array}$ \\
\hline \multirow[t]{9}{*}{ Roy, R. } & $\begin{array}{l}\text { de } \\
\text { Beuvron, F. }\end{array}$ & Nyhuis, P. & Bokrantz, J. & Janak, L. & Lucke, D. & $\begin{array}{l}\text { Sénéchal, } \\
\text { O. }\end{array}$ \\
\hline & Ferrise, F. & $\begin{array}{l}\text { Schneider, } \\
\text { M. }\end{array}$ & Cao, Q. & Jussen, $\mathrm{P}$. & Mourtzis, D. & Skoogh, A. \\
\hline & $\begin{array}{l}\text { Fiorentino, } \\
\text { M. }\end{array}$ & Stahre, J. & Deng, D. J. & Kans, M. & Negri, E. & Stark, R. \\
\hline & Found, P. & $\begin{array}{l}\text { Uhlmann, } \\
\text { E. }\end{array}$ & $\begin{array}{l}\text { Emmanouilidi } \\
\mathrm{s}, \mathrm{C} \text {. }\end{array}$ & Killi, A. & $\begin{array}{l}\text { Patalas- } \\
\text { Maliszewska, J. }\end{array}$ & Wang, Z. \\
\hline & $\begin{array}{l}\text { Gattullo, } \\
\text { M. }\end{array}$ & Uva, A. E. & Erkoyuncu, J & Kohl, J. & Plapper, P. & Weber, C. \\
\hline & Geisert, C. & Wuest, T. & $\begin{array}{l}\text { Fleischmann, } \\
\text { H. }\end{array}$ & $\begin{array}{l}\text { Königsberge } \\
\text { r, J. }\end{array}$ & Quirico, M. & $\begin{array}{l}\text { Winkens, } \\
\text { M. }\end{array}$ \\
\hline & $\begin{array}{l}\text { Hohwieler, } \\
\text { E. }\end{array}$ & $\begin{array}{l}\text { Zanni- } \\
\text { Merk, C. }\end{array}$ & Franke, J. & $\begin{array}{l}\text { Laghmouchi } \\
\text {, A. }\end{array}$ & Rakyta, M. & $X u, X$ \\
\hline & & & Fusko, M. & Li, D. & Reich, C. & Zeng, $\mathrm{P}$. \\
\hline & & & Giustozzi, F. & Li, L. & Rondi, M. & \\
\hline
\end{tabular}

Fonte: Os Autores.

Entre as áreas de pesquisa definidas pelas bases e de acordo com a Tabela 5, a categoria Engenharia é a mais ampla, com maior número de artigos associados $(n=34,1 \%)$, seguida de Ciência da Computação ( $n=20,7 \%$ ). Adverte-se que nas bases de dados, os artigos podem estar associados a mais de uma categoria ao mesmo tempo. 


\begin{tabular}{|c|c|c|}
\hline Rank & Área de Pesquisa & $\%$ \\
\hline 1은 & Engenharia & $34,1 \%$ \\
\hline 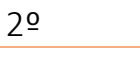 & Ciência da Computação & $20,7 \%$ \\
\hline 3으 & Negócios, Gerenciamento, Contabilidade & $8,6 \%$ \\
\hline $4 \stackrel{0}{\circ}$ & Instrumentação & $6,4 \%$ \\
\hline 50 & Automação & $5,1 \%$ \\
\hline 60 & Ciência dos Materiais & $4,9 \%$ \\
\hline $7 \underline{0}$ & Matemática & $4,7 \%$ \\
\hline 80 & Pesquisa Operacional & $3,9 \%$ \\
\hline 90 & Química & $3,5 \%$ \\
\hline 10 은 & Telecomunicações & $3,4 \%$ \\
\hline
\end{tabular}

Fonte: Os Autores.

Em seguida, foram identificados os periódicos nos quais os artigos aqui considerados foram publicados. Essa medida é relevante por indicar os periódicos científicos com maior destaque na área pesquisada, já que são as fontes de geração de conhecimento das quais se utilizam os pesquisadores do tema (Silva, 2002).

O maior número de artigos publicados sobre o tema aqui estudado foi observado no Procedia CIRP ( $n=25$ artigos, 11,1\%). Nos 16 periódicos com maior número de publicações, os temas produção e computação, foram os de maior destaque como mostra a Tabela 6. 


\begin{tabular}{|c|c|c|c|}
\hline Rank & Periódicos & Artigos & $\%$ \\
\hline 10 & Procedia CIRP & 25 & $11,1 \%$ \\
\hline 20 & IFAC-PapersOnLine & 10 & $4,4 \%$ \\
\hline $3 ㅇ$ & Procedia Manufacturing & 9 & $4,0 \%$ \\
\hline $4 ㅇ$ & MM Science Journal & 6 & $2,7 \%$ \\
\hline \multirow{2}{*}{50} & The International Journal of Advanced Manufacturing Technology & 5 & $2,2 \%$ \\
\hline & WT Werkstattstechnik & 5 & $2,2 \%$ \\
\hline \multirow{3}{*}{60} & Computers in Industry & 4 & $1,8 \%$ \\
\hline & IEEE Access & 4 & $1,8 \%$ \\
\hline & Procedia Computer Science & 4 & $1,8 \%$ \\
\hline \multirow{7}{*}{70} & Advances in Mechanical Engineering & 3 & $1,3 \%$ \\
\hline & Atp Edition & 3 & $1,3 \%$ \\
\hline & Chernye Metally & 3 & $1,3 \%$ \\
\hline & Computers \& Industrial Engineering & 3 & $1,3 \%$ \\
\hline & IEEE Transactions on Industrial Informatics & 3 & $1,3 \%$ \\
\hline & International Journal of Production Economics & 3 & $1,3 \%$ \\
\hline & International Journal of Production Research & 3 & $1,3 \%$ \\
\hline
\end{tabular}

Fonte: Os autores.

\subsection{As palavras-chave e as tecnologias habilitadoras mais utilizadas}

A partir da pesquisa bibliométrica, foi possível desenvolver uma nuvem de palavras-chave. Em uma visualização deste tipo, cada palavra tem seu tamanho regido pela relevância em determinado conjunto de texto. Neste caso, se trata da contagem simples das ocorrências de determinada palavrachave no conjunto de palavras-chave dos 225 artigos estudados. A Figura 2 ilustra a quantidade de vezes em que as palavras-chave, de forma isolada, apareceram dentro dos documentos analisados.

Figura 2

Nuvem da frequência de palavras-chave na produção científica 


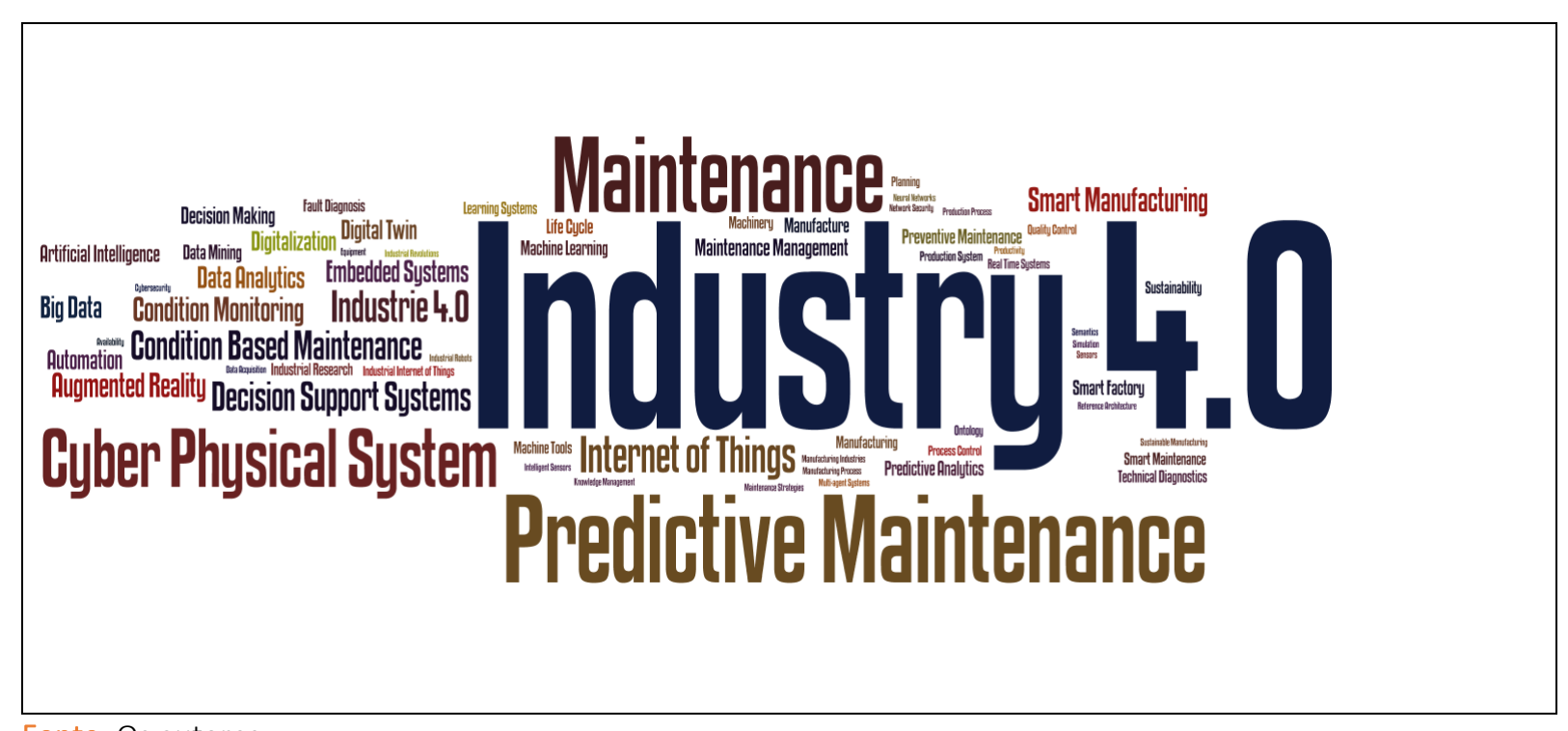

Fonte: Os autores.

A palavra Industry 4.0 foi citada 85 vezes na seção de palavras-chave dos artigos pesquisados, portanto, apresenta um tamanho proporcionalmente maior do que a sentença Predictive Maintenance, citada 36 vezes, e Maintenance, de forma isolada com 31 citações.

Outras sentenças que foram citadas mais de 10 vezes, em ordem decrescente são: Cyber Physical System, Internet of Things, Industrie 4.0, Condition Based Maintenance, Decision Support Systems, Augmented Reality, Condition Monitoring e Smart Manufacturing.

No total, foram encontradas 1353 palavras-chave distintas, o que resulta em uma média de 6,01 palavras por artigo. Deste total, 703 palavras-chave foram citadas somente uma vez e, 124 palavraschave foram citadas entre 2 e 9 vezes.

Com relação às tecnologias habilitadoras da Indústria 4.0, as mais citadas nos artigos estudados, em ordem decrescente são: Internet das coisas, Sistemas Ciber Físicos, Big Data, Computação em Nuvem, Simulação, Inteligência Artificial, Machine Learning, Otimização em tempo real, Realidade Aumentada, entre outros, conforme demonstra a Figura 3.

Figura 3

Frequência absoluta do número de tecnologias habilitadoras da Indústria 4.0 


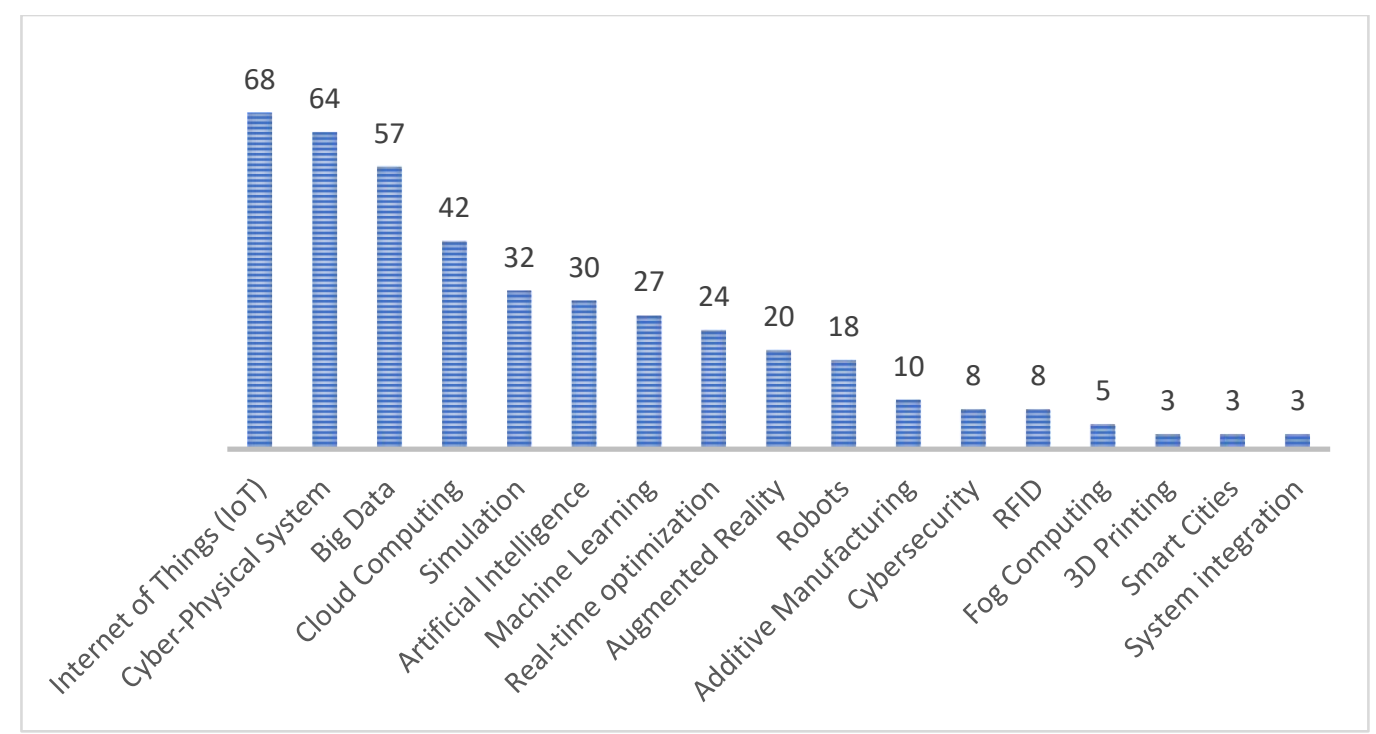

Fonte: Os Autores.

\subsection{Análise de conteúdo dos artigos}

Com base na análise bibliométrica, 7 artigos se destacaram para a realização de uma análise mais detalhada sobre a abordagem apresentada por cada autor sobre a questão da Indústria 4.0 e manutenção. O Quadro 3 apresenta os artigos selecionados nas bases de dados para discussão, bem como as contribuições dos estudos sobre o tema de geração de economia de recursos no custo de manutenção e outras características. 



\section{Quadro 3}

Relação de trabalhos relacionados para discussão

\begin{tabular}{|c|c|c|c|c|}
\hline Autor(es) & Objetivo & Método & Tecnologias & Contribuiç̧̃̃es \\
\hline Mourtzis e Vlachou (2018) & $\begin{array}{l}\text { Apresentar um sistema ciber-físico baseado } \\
\text { na computação em nuvem para o } \\
\text { agendamento de manutenções no chão de } \\
\text { fábrica. }\end{array}$ & $\begin{array}{l}\text { Estudo de caso: Indústria de } \\
\text { moldes }\end{array}$ & $\begin{array}{l}\text { Sistema Cyber Físico, Computação } \\
\text { em Nuvem, loT }\end{array}$ & $\begin{array}{l}\text { Contribui para a digitalização de empresas de manufatura, fornecendo um sistema } \\
\text { confiável, reconfigurável e com abordagem econômica, que apoiará as empresas na } \\
\text { mudança de maneira de fabricar, aumentando sua produtividade, aumentando sua } \\
\text { conscientização e redução de falhas imprevistas. Também propõe um sistema de } \\
\text { monitoramento de baixo custo, que é capaz de recuperar dados de várias fontes e transmitir } \\
\text { esses dados por meio de uma rede de sensores sem fio utilizando-se de protocolos de } \\
\text { comunicação. }\end{array}$ \\
\hline He, Han, Gu e Chen (2018) & $\begin{array}{l}\text { Propor um novo modelo de manutenção } \\
\text { preditiva orientada a custos. }\end{array}$ & $\begin{array}{l}\text { Estudo de caso: Indústria de } \\
\text { cabeçotes }\end{array}$ & Sistema Cyber Físico, Big Data & $\begin{array}{l}\text { A manutenção preditiva é realizada quando a confiabilidade do sistema atinge seu limite. A } \\
\text { estratégia de manutenção preditiva ideal é obtida minimizando os custos, incluindo custos } \\
\text { de manutenção corretiva e preditiva, bem como as perdas de capacidade de produção, } \\
\text { perdas indiretas e perdas de qualidade. }\end{array}$ \\
\hline $\begin{array}{l}\text { Guizzi, Falcone e De Felice } \\
\text { (2019) }\end{array}$ & $\begin{array}{l}\text { Definir um modelo de simulação para } \\
\text { gerenciamento integrado do processo de } \\
\text { produção e manutenção. }\end{array}$ & Simulação & Software PowerSim ${ }^{\circledast}$ & $\begin{array}{l}\text { O modelo de simulação desenvolvido no estudo proporciona um laboratório virtual, onde é } \\
\text { possível a realização de experimentos para a compreensão do comportamento das } \\
\text { atividades de manutenção, possibilitando a avaliação de custos e benefícios. }\end{array}$ \\
\hline $\begin{array}{l}\text { Bengtsson e Lundström } \\
\text { (2018) }\end{array}$ & $\begin{array}{l}\text { Exemplificar a importância de combinar } \\
\text { conceitos e gerenciamento básicos de } \\
\text { manutenção com avanço tecnológico da } \\
\text { Indústria } 4.0 \text { para aumentar a eficácia total da } \\
\text { manutenção. }\end{array}$ & $\begin{array}{l}\text { Estudo de caso: Cabine de } \\
\text { pintura }\end{array}$ & Sistema Cyber Físico, loT, Big Data & $\begin{array}{l}\text { Onde a manutenção preditiva não é necessária, ou onde não é economicamente viável ou } \\
\text { onde nem mesmo é possível, o foco ainda precisa ser direcionado para os conceitos básicos } \\
\text { de manutenção e gerenciamento. Também recomenda-se que os usuários de máquinas } \\
\text { compartilhem os dados e experiências com fornecedores destes equipamentos e vice-versa, } \\
\text { de modo que aprimoramentos nas próximas gerações de produtos possam ser realizados no } \\
\text { projeto em vez de ocorrerem falhas na execução, por meio de análises de causa raiz, } \\
\text { elevando os custos envolvidos. }\end{array}$ \\
\hline $\begin{array}{l}\text { Romero-Torres, Moyne e } \\
\text { Kidambi (2017) }\end{array}$ & $\begin{array}{l}\text { Verificar a oportunidade de adotar técnicas } \\
\text { da Indústria } 4.0 \text { utilizadas por uma indústria } \\
\text { de semicondutores na indústria farmacêutica. }\end{array}$ & Pesquisa descritiva & Sistema Cyber Físico, Big Data, loT & $\begin{array}{l}\text { Aproveitar as lições aprendidas no segmento de semicondutores deve beneficiar muito a } \\
\text { indústria farmacêutica e o sistema de saúde, ao mesmo tempo que minimiza o custo e os } \\
\text { riscos associados à adoção de sistemas revolucionários. }\end{array}$ \\
\hline Tedeschi et al. (2018) & $\begin{array}{l}\text { Estabelecer as bases para a criação de um } \\
\text { modelo conceitual inovador para estimar o } \\
\text { custo da implementação de novas } \\
\text { arquiteturas da Indústria } 4.0 \text { para sistemas }\end{array}$ & Estudo de caso: CAM-SMILS & $\begin{array}{l}\text { Sistema Cyber Físico, Computação } \\
\text { em Nuvem, loT }\end{array}$ & $\begin{array}{l}\text { O artigo apresenta o modelo CAM-SMILS que visa ser uma solução conceitual para avaliar o } \\
\text { custo de implantação de diferentes arquiteturas de loT. Os resultados beneficiam as } \\
\text { organizações por meio da solução conceitual proposta para estimar e comparar entre o } \\
\text { custo de diferentes arquiteturas de loT para seus sistemas. }\end{array}$ \\
\hline $\begin{array}{l}\text { Adu-Amankwa, Attia, } \\
\text { Janardhanan e Patel (2019) }\end{array}$ & $\begin{array}{l}\text { Propor uma arquitetura de sistema de } \\
\text { manutenção preditiva econômica de } \\
\text { máquinas CNC para pequenas e médias } \\
\text { empresas que prevê economias de custos. }\end{array}$ & Pesquisa exploratória e Survey & $\begin{array}{l}\text { Sistema Cyber Físico, Computação } \\
\text { em Nuvem, loT }\end{array}$ & $\begin{array}{l}\text { Propôs um sistema de manutenção econômico para oficinas de máquinas CNC, que prevê } \\
\text { economias de custos que varia de } £ 22.804 \text { a } 488.585 \text { em ferramentas de usinagem CNC. }\end{array}$ \\
\hline
\end{tabular}

Fonte: Os Autores. 
Mourtzis e Vlachou (2018) apresentaram um sistema ciber-físico baseado na computação em nuvem para o agendamento de manutenções no chão de fábrica. O sistema proposto demonstrou que é possível implantar, de forma econômica e confiável, uma coleta, processamento e análise de dados em tempo real no chão de fábrica. Também demonstrou que os dados coletados podem ser usados em um sistema de tomada de decisão adaptável, por meio de um algoritmo de tomada de decisão com vários critérios, além de uma estratégia de manutenção baseada em condições, melhorando o desempenho da fábrica quando comparado às abordagens tradicionais. A abordagem proposta consistiu em diferentes módulos interconectados por meio de uma plataforma em nuvem, habilitada por protocolos de comunicação sob os paradigmas da Indústria 4.0 e loT. O sistema proposto foi aplicado e validado em um estudo de caso real de uma indústria de moldes de alta precisão. Segundo os autores, o controle adaptativo da manutenção pode ser realizado e as empresas podem aumentar sua competitividade fornecendo produtos novos e existentes com rapidez e eficiência, além de baixo custo e alta qualidade.

De modo a maximizar os benefícios, He et al. (2018) propuseram um novo modelo de manutenção preditiva orientada a custos, baseada no estado de confiabilidade dos sistemas de manufatura. Utilizou-se um sistema ciber-físico para organizar e analisar o Big Data no processo operacional dos sistemas de manufatura em termos de análise preditiva. Após isso foi definido, com base no Big Data, as condições do equipamento e o grau da tarefa da produção. Então, definiu-se que o modo de manutenção preditiva baseado no estado de confiabilidade da missão é quantificado pelo custo, e o relacionamento entre a confiabilidade e o custo da missão foi estabelecido. Assim, pode-se propor uma estratégia de manutenção preditiva dinâmica orientada a custos. Ao final, elaborou-se um estudo de caso sobre o problema de tomada de decisão de manutenção de um sistema de fabricação de cabeçotes. O resultado demonstrou que o custo pode ser reduzido ainda mais pelo método proposto em relação à estratégia de manutenção preventiva tradicional.

A pesquisa de Guizzi et al. (2019) definiu um modelo de simulação para gerenciamento integrado do processo de produção e manutenção. Desse modo, foi desenvolvida uma estrutura para a implementação de modelos de simulação que possam auxiliar os gerentes de produção e manutenção a tomar decisões mais econômicas e otimizar o uso de recursos. A abordagem System Dynamics foi utilizada para simular, por meio do software PowerSim ${ }^{\circledR}$, o comportamento não linear dos sistemas complexos analisados ao longo do tempo. O resultado da otimização foi representado por valores ótimos de limiares de manutenção preventiva, preditiva e corretiva, em relação não apenas aos custos fixos de manutenção e aos custos variáveis de desligamento da produção, mas também em relação a valores particulares da falha e intervalo planejado para a atividade de inspeção. Os resultados revelaram que o procedimento de otimização de simulação proposto pode ser usado para resolver e gerenciar a complexidade em tempo real. Além disso, os dados do procedimento de otimização de simulação 
fornecem ao tomador de decisão o cenário mais provável. Bengtsson e Lundström (2018), por meio de um estudo de caso, exemplificaram a importância de combinar conceitos e gerenciamento básicos de manutenção, por exemplo, gerenciamento precoce de equipamentos, manutenção preventiva predeterminada e análise e eliminação de falhas de causa raiz, com avanço tecnológico, como manutenção preditiva, sistemas ciber físicos, internet das coisas e big data, para aumentar a eficácia total da manutenção. Entre outros resultados, a pesquisa relata que onde a manutenção preditiva não é necessária, ou onde não é economicamente viável ou onde nem é possível, o foco ainda precisa ser direcionado para conceitos e gerenciamento básicos de manutenção. Além disso, recomenda-se sempre que possível, que os usuários dos equipamentos compartilhem dados e experiências com os fornecedores de equipamentos e vice-versa, para que melhorias nas próximas gerações possam ser realizadas na engenharia do produto em vez de executar problemas através de um loop muito mais caro de manutenção preditiva.

Romero-Torres, Moyne e Kidambi (2017) verificaram a oportunidade de adotar técnicas da Indústria 4.0 utilizadas por uma indústria de semicondutores do Vale do Silício na indústria farmacêutica. Entre outros fatores, o estudo apontou que a manutenção preditiva está recebendo considerável atenção na fabricação de semicondutores, porque está focada na redução do tempo de inatividade não programado, que é uma das principais fontes de perda de qualidade. e custo na fabricação. A maioria das soluções envolvem recursos de mineração e análise de dados para desenvolver modelos que não apenas prevejam a ocorrência futura de uma falha de equipamento ou componente, mas também indique o horizonte da vida útil do material, bem como a confiabilidade e o alcance da previsão. O trabalho ainda traz um exemplo de aplicação de manutenção preditiva 4.0 implantado na fabricação de semicondutores. Nesta aplicação, um modelo de modo de falha multivariada foi usado para estimar um índice que dispara um alarme quando dispositivos de aquecimento (lâmpadas) precisam ser substituídos. Antes da implementação dessa estratégia, o usuário executava as lâmpadas com falha, resultando em tempo de inatividade e sucata não programados, ou usava técnicas simples de detecção de falhas para detectar falhas iminentes. Com a adoção do novo modelo, a planta pode prever falhas com cinco dias antecipados. Esse horizonte de tempo de falha permitiu que a planta otimizasse o cronograma de manutenção. A precisão da previsão deste modelo de modo de falha é superior a $80 \%$.

Tedeschi, Rodrigues, Emmanouilidis, Erkoyuncu, Roy e Starr. (2018) estabelecem as bases para a criação de um modelo conceitual inovador para estimar o custo da implementação de novas arquiteturas da Indústria 4.0 em sistemas já instalados. A abordagem proposta considera aspectos que impactam o custo de diferentes arquiteturas de loT, como: complexidade, protocolos de coleta e compartilhamento de dados e segurança cibernética. Os autores sugerem uma implementação adicional do modelo de custo, a fim de orientar as organizações na arquitetura mais econômica para 
modernização de seus sistemas. Os pesquisadores apresentaram o modelo CAMSMILS que visa ser uma solução conceitual para avaliar o custo de implementação de diferentes arquiteturas de IoT. Uma característica importante do CAM-SMILS é a capacidade de executar a avaliação do custo com base em dados qualitativos de entrada. Assim, decisões podem ser tomadas com base em uma rápida avaliação e relativamente fácil sobre o conceito de loT, considerando aspectos subjetivos e dificilmente quantificáveis, como complexidade, velocidade e segurança.

Adu-Amankwa, Attia, Janardhanan, e Pat (2019) propõem uma arquitetura de sistema de manutenção preditiva econômica de máquinas CNC para pequenas e médias empresas que prevê economias de custos. Os dados obtidos por meio da survey mostraram algumas vantagens da manutenção preditiva: a relação inversamente proporcional entre taxa de falha e manutenção, tempo de inatividade e perda de custo de produtividade, disponibilidade e eficácia geral da máquina. No entanto, os autores reconhecem que resultado do modelo requer um próximo estágio de verificação participativa, que forneçam informações de dados reais após a implementação da arquitetura do sistema proposto.

\section{Discussão}

Portanto, como demonstra o Quadro 3, há uma diversidade de tecnologias habilitadoras que vêm sendo exploradas e comparadas com a intenção de prover novas funcionalidades aos modelos existentes. Por meio da análise de conteúdo dos artigos e suas contribuições para a literatura, verificase que com a aplicação de recursos tecnológicos, a Indústria 4.0 garante mais eficiência às empresas, gerando oportunidades de otimizar receitas no custo de manutenção de ativos e obter melhores resultados, criando vantagem competitiva.

As tecnologias da Indústria 4.0 contribuem para menos ocorrências de paradas na produção, evitando-se ações emergenciais (Mourtzis \& Vlachou, 2018; Guizzi et al., 2019; Bengtsson \& Lundström, 2018; Romero-Torres et al., 2017; Tedeschi et al., 2018).

A adesão às tecnologias da Indústria 4.0 propicia um avanço na manutenção preditiva, ou seja, faculta monitorar os equipamentos de forma constante de modo a prever falhas de maneira prematura (He et al., 2018; Guizzi et al., 2019; Bengtsson \& Lundström, 2018; Romero-Torres et al., 2017; Tedeschi et al., 2018; Adu-Amankwa et al., 2019).

A manutenção é realizada por meio de sensores que são acoplados nos equipamentos e enviam informações para a computação em nuvem através de sistemas específicos (Mourtzis \& Vlachou, 2018; Romero-Torres et al., 2017; Bengtsson \& Lundström; Tedeschi et al., 2018; Adu-Amankwa et al., 2019).

Recursos como o Big Data também ajudam a melhorar as condições de trabalho. Isso pode se manifestar em maior produtividade e rentabilidade para a empresa (He et al.,2018; Bengtsson \& Lundström, 2018; Romero-Torres et al., 2017). Constata-se também que as vantagens das tecnologias 
da Indústria 4.0 não dependem necessariamente de uma transformação completa na estrutura. É possível utilizar e adaptar equipamentos para este novo modelo, e garantir um salto de produtividade, eficiência e redução de custos na manutenção de ativos.

Ao final desta análise bibliográfica, percebe-se que apesar de se encontrar trabalhos relevantes, a literatura a respeito da Indústria 4.0 ainda está dando os primeiros passos, principalmente com relação à aplicação prática das tecnologias habilitadoras na manutenção, seja por meio de estudos de caso ou outros métodos. Contudo, existe um desafio para esse tipo de pesquisa: os modelos propostos devem incorporar os aspectos reais da operação e das especificações de manutenção dos ativos, o que acaba por se tornar uma grande oportunidade para a realização de pesquisas futuras.

O trabalho de Mourtzis e Vlachou (2018) sugere como pesquisa futura que os dados capturados do sistema de monitoramento sejam também utilizados para prever o consumo de energia e planejamento de manutenção. He et al. (2018) propoem integrar outros tipos de custos durante a otimização de um sistema, como o custo de mão de obra. No entanto, Guizzi et al. (2019) recomenda outras naturezas de custos, como os fixos e os variáveis. Bengtsson e Lundström (2018) inspiram a incorporar alguns desafios que os engenheiros e cientistas da computação enfrentam, como uma grande quantidade de dados gerados (Big Data), além de estudar a forma mais adequada de compreender, utilizar e armazenar os dados. Romero-Torres et al. (2017) instigam a verificar e comparar as lições de inovação da indústria de semicondutores com relação a outros segmentos de indústria. Tedeschi et al. (2018) sugerem a implementação do modelo CAM-SMILS em outra plataforma prática de simulação, de forma a avaliar e validar outros cenários. Os autores também propoem aplicar o modelo a diferentes arquiteturas de IoT, de modo a permitir uma comparação entre o custo de implementação de cada uma e identificar o mais adequado para um determinado cenário. AduAmankwa et al. (2019) propoem abordar em pesquisas futuras o grau de prontidão de empresas de serviços de usinagens com máquinas CNC para a Indústria 4.0. Além disso, explorar a respeito de problemas associados às informações, segurança e proteção de dados.

Outro ponto que pode ser observado nos artigos estudados foi a ausência ou diminuta produção bibliográfica explorando soluções para questões sobre as tecnologias, implantação, planejamento e controle da manutenção, segurança, recursos humanos e qualidade dos serviços voltados à manutenção de ativos. São oportunidades de pesquisas futuras que alinhem tecnologias (como a realidade aumentada, visão artificial, digital twin e robôs colaborativos) que podem ser utilizadas na manutenção de ativos, com o estudo de mapeamento de processos, além dos processos de manutenção, toda a cadeia produtiva da empresa, gerando melhores receitas, redução de custos, flexibilização e eliminação de desperdícios.

\section{Considerações Finais}

Exacta, 21(1), p. 23-52, jan./mar. 2023 
Como se observou, este estudo alcançou o objetivo inicialmente proposto, já que foi investigada na literatura a produção científica a respeito da manutenção de ativos na era da Indústria 4.0 em três diferentes bases de dados, no período entre 2014 e 2019.

Diferentes aspectos foram estudados por meio de dados estatísticos e suas respectivas análises. Dessa forma, as técnicas bibliométricas demonstram que a pesquisa pode ser de utilidade para a descoberta da produção científica na área, sendo que os dados contidos neste artigo podem ser utilizados como ferramenta tanto para o planejamento como para a execução de estudos, visando melhor compreender a ciência pela comunidade científica, empresarial e outros segmentos da sociedade.

No contexto da manutenção na era da Indústria 4.0, verifica-se ainda uma carência e necessidade de estudos de aplicações práticas, que proporcionem uma aprendizagem adequada e que ajude no entendimento e melhoria das tecnologias. Assim, este trabalho traz contribuições teóricas na medida que identificou lacunas de pesquisa e sugeriu algumas oportunidades a serem consideradas em estudos futuras sobre o tema, auxiliando a Academia a melhor adequar a Manutenção 4.0, suas configurações e necessidades. Para a prática da Engenharia de Produção e da Gestão de Operações, os conhecimentos aqui expostos poderão se tronar um guia aos gestores das áreas de Manutenção sobre os principais tópicos que associam a manutenção de ativos e os requisitos das tecnologias da l 4.0 como forma de maximizar o desempenho dos equipamentos, potencializar a geração de economia de recursos nos custos, e contribuindo para um melhor posicionamento nesse mercado competitivo no qual as empresas hoje se inserem.

Como toda pesquisa, esta também possui limitações. A mais significante se refere ao fato de que foram consideradas somente três bases de dados (Science Direct, Scopus e Web of Science), devido ao grande volume de publicações e a popularidade na área de engenharia e ciência da computação, No entanto, isso não significa que outras bases de dados igualmente relevantes como fonte do conhecimento científico não possam trazer mais contribuições ao estudo desenvolvido. Também pode se constituir em limitação o conjunto de palavras chave utilizadas. Provavelmente a inclusão de mais termos, suas cognatas e diferentes combinações poderão trazer na busca da literatura outros artigos que possam contribuir com a análise aqui realizada. Consequentemente, futuros trabalhos poderiam considerar a utilização de outras bases de busca. Ademais, recomenda-se utilizar outras palavras chave relacionadas ao tema e que não foram utilizadas neste trabalho, obtendo-se novas informações e realizando outras análises que não foram consideradas neste artigo. 


\section{Referências}

ABRAMAN - Associação Brasileira de Manutenção e Gestão de Ativos. (2013). A situação da manutenção no Brasil. Anais do 28o Congresso Brasileiro de Manutenção. Salvador: Abraman.

Al-Ahmari, A., \& Li, Z. (2016). Analysis of a multimachine flexible manufacturing cell using stochastic Petri nets. Advances in Mechanical Engineering, 8(11), 1-9. Retrieved June 10, 2020, from https://doi.org/10.1177/1687814016680168.

Al-Gumaei, K., Schuba, K., Friesen, A., Heymann, S., Pieper, C., Pethig, F., \& Schriegel, S. (2018). A survey of internet of things and big data integrated solutions for industrie 4.0. IEEE 23rd International Conference on Emerging Technologies and Factory Automation, 23(1), 14171424.

Alrabghi, A., Tiwari, A., \& Savill, M. (2017). Simulation-based optimisation of maintenance systems: Industrial case studies. Journal of Manufacturing Systems, 44, 191-206.

Adu-Amankwa, K., Attia, A. K., Janardhanan, M. N., \& Patel, I. (2019). A predictive maintenance cost model for CNC SMEs in the era of industry 4.0. The International Journal of Advanced Manufacturing Technology, 104(9-12), 3567-3587. Retrieved June 10, 2020, from https://doi.org/10.1007/s00170-019-04094-2.

Antosz, K., \& Ratnayake, R. C. (2019). Spare parts' criticality assessment and prioritization for enhancing manufacturing systems' availability and reliability. Journal of Manufacturing Systems, 50, 212-225. 
Arnold, C., Kiel, D., \& Voigt, K. I. (2016). How the industrial internet of things changes business models in different manufacturing industries. International Journal of Innovation Management, 20(08), 1640015.

Associação Brasileira de Normas Técnicas. (1994). NBR 5462 - Confiabilidade e mantenabilidade. São Paulo: ABNT.

Babiceanu, R. F., \& Seker, R. (2016). Big data and virtualization for manufacturing cyber-physical systems: a survey of the current status and future outlook. Computers in Industry, 81, 128137.

Barros, J. F., \& Lima, G. (2011). A gestão da manutenção no plano estratégico dos empreendimentos industriais. Congresso Nacional de Excelência em Gestão, 7.

Bengtsson, M., \& Lundström, G. (2018). On the importance of combining "the New" with "the Old"one important prerequisite for maintenance in Industry 4.0. Procedia Manufacturing, 25, 118125.

Blanchard, B. (2003). Logistics engineering and management (6a. ed.). Englewwod Cliffs: Prentice Hall.

Branco Filho, G. (2008). Organização, o planejamento e o controle da manutenção. Rio de Janeiro: Ciência Moderna.

Brettel, M., Friederichsen, N., Keller, M., \& Rosenberg, M. (2014). How virtualization, decentralization and network building change the manufacturing landscape: An Industry 4.0 
perspective. International Journal of Mechanical, Industrial Science and Engineering, 8(1), 3744.

Campos, V. F. (2013). Gerenciamento da Rotina do trabalho do dia a dia. 9. Ed. Nova Lima: FALCONI Editora.

Changyou, L., Haiyang, L., Song, G., Yimin, Z., \& Zhenyuan, L. (2014). Gradual Reliability Sensitivity Analysis of Mechanical Part Considering Preventive Maintenance. Advances in Mechanical Engineering.

Choi, S. S., Kang, G., Jung, K., Kulvatunyou, B. \& Morris, K.C. (2016). Applications of the factory design and improvement reference activity model. International Conference on Advances in Production Management Systems (APMS), Iguassu Falls, Brazil. Retrieved June 10, 2020, from https://hal.inria.fr/hal-01615741/document.

del Amo, I. F., Erkoyuncu, J. A., Roy, R., \& Wilding, S. (2018). Augmented Reality in Maintenance: An information-centred design framework. Procedia Manufacturing, 19, 148-155.

Dillon, T., Wu, C., \& Chang, E. (2010). Cloud Computing: Issues and Challenges. Proceedings. International Conference on Advanced Information Networking and Applications, AINA, 27-33.

Ding, S. H., \& Kamaruddin, S. (2015). Maintenance policy optimization - literature review and directions. The International Journal of Advanced Manufacturing Technology, 76(5-8), 12631283. 
European Parliament. (2015). Industry 4.0 Digitalisation for productivity and

growth. Retrieved June 10, 2020, from

http://www.europarl.europa.eu/RegData/etudes/BRIE/2015/568337/EPRS_BRI

(2015)568337_EN.pdf.

Erol, S., Jäger, A., Hold, P., Ott, K., \& Sihn, W. (2016). Tangible Industry 4.0: a scenario-based approach to learning for the future of production. Procedia Cirp, 54(1), 13-18.

Gil, A. C. (2010). Métodos e técnicas de pesquisa social. (8a. ed.). São Paulo: Atlas.

Guizzi, G., Falcone, D., \& De Felice, F. (2019). An integrated and parametric simulation model to improve production and maintenance processes: towards a digital factory performance. Computers \& Industrial Engineering, 137, 106052.

He, Y., Gu, C., Chen, Z., \& Han, X. (2017). Integrated predictive maintenance strategy for manufacturing systems by combining quality control and mission reliability analysis. International Journal of Production Research, 55(19), 5841-5862.

He, Y., Han, X., Gu, C., \& Chen, Z. (2018). Cost-oriented predictive maintenance based on mission reliability state for cyber manufacturing systems. Advances in Mechanical Engineering, 10(1), 1-15. . Retrieved June 10, 2020, from https://journals.sagepub.com/doi/pdf/10.1177/1687814017751467.

Herrmann, C., Schmidt, C., Kurle, D., Blume, S., \& Thiede, S. (2014). Sustainability in manufacturing and factories of the future. International Journal of Precision Engineering and ManufacturingGreen Technology, 1, 283-292. 
Hirsch-Kreinsen, H. (2014). Smart production systems: a new type of industrial process innovation. DRUID Society Conference.

Jasiulewicz-Kaczmarek, M., \& Gola, A. (2019). Maintenance 4.0 Technologies for Sustainable Manufacturing-an Overview. IFAC-PapersOnLine, 52(10), 91-96.

Lee, J., Bagheri, B., \& Kao, H. A. (2015). A cyber-physical systems architecture for industry 4.0 - based manufacturing systems. Manufacturing Letters, 3, 18-23.

Lee, J., Kao, H. A., \& Yang, S. (2014). Service innovation and smart analytics for Industry 4.0 and big data environment. Procedia CIRP, 16, 3-8.

Li, Z., Wang, Y., \& Wang, K. S. (2017). Intelligent predictive maintenance for fault diagnosis and prognosis in machine centers: Industry 4.0 scenario. Advances in Manufacturing, 5(4), 377387.

Lopes, I., Senra, P., Vilarinho, S., Sá, V., Teixeira, C., Lopes, J., Alves, A., Oliveira, J., \& Figueiredo, M. (2016). Requirements specification of a computerized maintenance management system-a case study. Procedia Cirp, 52(1), 268-273.

Mirshawka, V. \& Olmedo, N. L. (1993). Manutenção - combate aos custos da não eficácia - a vez do Brasil. São Paulo: Makron Books.

Mobley, R. K. (2002). An introduction to predictive maintenance. São Paulo: Elsevier. 
Moraes, E. C., \& Lepikson, H. A. (2017). Industry 4.0 and its impacts on society. Proceedings of the International Conference on Industrial Engineering and Operations Management, 25-26.

Mourtzis, D., \& Vlachou, E. (2018). A cloud-based cyber-physical system for adaptive shop-floor scheduling and condition-based maintenance. Journal of manufacturing systems, 47, 179-198.

Mueller, E., Chen, X. L., \& Riedel, R. (2017). Challenges and requirements for the application of industry 4.0: a special insight with the usage of cyber-physical system. Chinese Journal of Mechanical Engineering, 30(5), 1050-1057.

Pinto, J. P. (2013). Manutenção lean. Lisboa: Lidel.

Rødseth, H., Schjølberg, P., \& Marhaug, A. (2017). Deep digital maintenance. Advances in Manufacturing, 5(4), 299-310.

Romero-Torres, S., Moyne, J., \& Kidambi, M. (2017). Towards Pharma 4.0; leveraging lessons and innovation from Silicon Valley. American Pharmaceutical Review, 5, 132-141.

Roy, R., Stark, R., Tracht, K., Takata, S., \& Mori, M. (2016). Continuous maintenance and the future foundations and technological challenges. Cirp Annals, 65(2), 667-688.

Slack, N., Brandon-Jones, \& Johnston, R. (2018). Administração da produção. (8a. ed.) São Paulo: Atlas. 
Silva, S. (2002). Comunicação organizacional em empresas de construção civil sob a ótica do planejamento estratégico. 157 f. Curitiba, 2002 (Dissertação) (Mestrado em Construção CivilPrograma de Pós-Graduação em Construção Civil, Universidade Federal do Paraná, Curitiba).

Stock, T., \& Seliger, G. (2016). Opportunities of sustainable manufacturing in industry 4.0. Procedia Cirp, 40, 536-541.

Suarez-Warden, F, Mendıvil, EG, Ramırez, AF, Garcı-Lumbreras, S., (2015), Profit Model for Incorporating AR Technology in Assembly Tasks of Aeronautical Maintenance. Procedia Computer Science, 75, 113-122.

Tedeschi, S., Rodrigues, D., Emmanouilidis, C., Erkoyuncu, J., Roy, R., \& Starr, A. (2018). A cost estimation approach for loT modular architectures implementation in legacy systems. Procedia Manufacturing, 19, 103-110.

Wan, J., Tang, S., Li, D., Wang, S., Liu, C., Abbas, H., \& Vasilakos, A. V. (2017). A manufacturing big data solution for active preventive maintenance. IEEE Transactions on Industrial Informatics, 13(4), 2039-2047.

Xia, T., Xi, L., Lee, J., \& Zhou, X. (2011). Optimal CBPM policy considering maintenance effects and environmental condition. International Journal of Advanced Manufacturing Technology. 56. 1181-1193.

Zhong, R.Y., Wang, L., \& Xu, X. (2017). An loT-enabled Realtime Machine Status Monitoring Approach for Cloud Manufacturing, Procedia CIRP, 63, 709-714. 